\title{
Segmenting and Targeting Your Markets: Strategies and Limitations
}

\author{
Michael Lynn
}

Almost any marketing textbook will tell you that the key to successful marketing can be summed up by the STP strategy - that is, segmentation, targeting, and positioning. ${ }^{1}$ This approach suggests that the mass market consists of some number of relatively homogeneous groups, each with distinct needs and desires. STP marketers attempt to identify those market segments, direct marketing activities at the segments which the marketers believe that their company can satisfy better than their competitors, and position their product offering so as to appeal to the targeted segments. Undoubtedly, your hospitality firm uses some form of this approach.

Critical to this strategic approach is selecting some segments to target and others to ignore. As David Aaker writes, "Positioning usually implies a segmentation commitment-an overt decision to ignore large parts of the market and concentrate only on certain segments." ${ }^{2}$ One reason this segmentation commitment is necessary is that the needs of different segments are often conflicting and their satisfaction mutually exclusive. For example, older consumers may prefer a quiet cruise, restaurant, hotel, or resort environment and might be put off by a loud, rock-based show that would appeal to younger consumers. Likewise, amenities and entertainment for families with children might not mesh with those of singles or seniors. Even if those features and amenities are not mutually exclusive, the cost of building a single product with all the features desired by different segments would drive costs to unreasonable levels.

Although STP marketing strategy involves segmentation commitment at the brand level, it does not preclude efforts to capture many different segments at the corporate level. Companies can pursue either a concentrated STP marketing strategy by offering a single brand to only one or two segments or a differentiated STP marketing strategy in which they strive to capture many different segments by targeting a different brand to each segment. ${ }^{3}$ Rosewood Hotels \& Resorts and Crystal Cruises, both of which are relatively small companies focusing on the luxury-seeking segment, exemplify a concentrated STP marketing strategy. Two firms that apply a differentiated STP marketing strategy are Choice Hotels International, which targets numerous lodging market segments with its many diverse brands (including EconoLodge, Cambria Suites, Clarion, Comfort Inn, and the Ascend Collection), and Carnival Corporation, 
which likewise targets numerous cruise market segments with its family of brands (including Carnival, Cunard, Holland America, Princess, and Seabourne). Thus, while STP marketing imposes limits on brand strategy, it does not preclude different corporate strategies and ambitions.

Although I discuss the commonly accepted approach to segmenting markets and selecting those segments to target in this chapter, I also want to explain about the limits of market segmentation. In particular, I want to caution you about relying too heavily on the best-known STP marketing strategyfrequent guest programs. Finally, I discuss appropriate strategies to pursue when you've reached the limits of market segmentation and segmentation commitment.

\section{How to Segment Markets and Select Target Segments}

Let's start with the classic segmentation concepts. To begin with, there is more than one way to segment a market. You may differentiate your customers on the basis of demographic variables (such as age, gender, education, and income), geographic variables (such as nation, state, region, and neighborhood type), psychographic variables (such as attitudes, opinions, interests, and values), and behaviors (such as media habits, purchase frequency, brand loyalty, and channel usage). Segmentation schemes have become quite sophisticated, using advanced statistics and numerous variables. For example, Nielsen Claritas uses geographic, demographic, and behavioral data to divide U.S. households into its different PRIZM segments. Nielsen gives these segments such fanciful names as "Blue Blood Estates," "Country Squires," and "Money \& Brains." ${ }^{4}$ Nielsen describes the Money \& Brains segment, as follows: "The residents of Money \& Brains seem to have it all: high incomes, advanced degrees, and sophisticated tastes to match their credentials. Many of these city dwellers, predominantly white with a high concentration of Asian Americans, are married couples with few children who live in fashionable homes on small, manicured lots."

You can identify whatever number of segments makes the most sense for your business. Segmenting the market on the basis of sex results in two segments, of course, but you may need to refine your segment definitions by adding other variables. Continuous variables like age typically give rise to three or more segments, such as young, middle aged, and elderly, and then you can combine these or other variables to create even more segments. The Nielsen Claritas' PRIZM segmentation divides the market into 66 different groups, but your business may not need to define your segments so tightly. ${ }^{6}$

So, which variables should you use to segment the market, and how many segments should you identify? No single answer to these questions applies across the board. Instead, the answer depends on 
your business, your market, and your customers. Different markets are best segmented using different types of variables and different numbers of segments. Most likely, the preexisting, generic market segmentations sold by marketing research firms will not be ideal for your situation. For this reason, you should conduct or commission segmentation studies of your own specific market-starting with literally hundreds of different variables, analyzing them, and gradually winnowing the list to see which ones produce segments or groupings of consumers that are most useful. ${ }^{7}$

The key point regarding segments is that to be useful, the segment groupings must contain consumers who are similar to one another and distinct from the consumers in other groups with respect to their responsiveness to your potential marketing offerings and appeals. ${ }^{8}$ In addition, the different segments should (1) differ in ways that allow their size and accessibility to be easily measured, (2) be large enough to justify separate targeting efforts, (3) be uniquely reachable via communication media and marketing channels, and (4) be relatively stable and not diminishing in size over time. ${ }^{9}$

Since the best STP approach is to conduct your own study, most market segmentation studies are proprietary and unavailable to the public. However, a good segmentation example of a local restaurant market was described in a 1986 article in the Cornell Quarterly, by William Swinyard and Kenneth Struman." 10

I explain this study in detail so that you can see how a market segmentation study might proceed. However, the process requires considerable expertise and time. As I outline later, you'll probably want to hire someone to conduct a study like this.

Swinyard and Struman first identified a large number of restaurant attributes that might influence consumer choice. Examples of such attributes were:

- A good place for meeting new people

- Consistent food quality from visit to visit

- Friendly service

- Large food portions

- A lively, upbeat environment

- A convenient location

- Attractive waiters and waitresses

Then they asked a sample of consumers to rate the market's restaurants on each attribute, as well as how appealing each attribute would be in an "ideal" restaurant. The respondents also rated the 
importance of each restaurant attribute, and their agreement with general lifestyle statements (such as, "I never seem to have enough money," "I love to cook," and "I like to meet lots of new people"). Finally, respondents reported on their recent dining-out experiences and provided detailed demographic information about themselves.

Swinyard and Struman analyzed ratings of an ideal restaurant on each attribute using a statistical technique called cluster analysis to identify groups or segments of consumers with relatively similar perceptions of that theoretical ideal restaurant. The authors didn't say this, but I suspect that the cluster analysis was probably performed only on the ratings for those attributes for which performance differed among existing restaurants in the market. I say this for two reasons. First, reasonably large and well-defined clusters typically emerge only when small numbers of variables are used to define the clusters. Second, attributes on which every restaurant performs reasonably well don't cause consumers to choose one restaurant over another, even if those attributes are important. As Swinyard and Struman wrote, "You must select clustering variable measures that describe the reasons a customer would choose your restaurant over another." ${ }^{11}$

After identifying the segments with cluster analysis, the researchers compared different groups or segments on the lifestyle factors, restaurant patronage patterns, and demographic variables. The results of all these analyses are presented in Table 23.1.

Although Swinyard and Struman did not share their detailed statistical results, based on the information they did share, this appears to be a good segmentation of the market because: (1) the segments differ from one another on restaurant patronage behavior and actionable drivers of consumer choice among restaurants, (2) the size of the segments could be estimated from their size in the survey sample, and (3) the segments were substantial enough in terms of share of patrons and dollars to warrant targeting. This segmentation would be even more useful if we knew whether the segments had different media usage patterns and geographic dispersions, so that restaurants could more costeffectively communicate with the target segment and make better site location decisions. But even without this information, the identified differences between the segments are more than adequate to guide marketing decisions.

With this explanation, you can see why segmentation studies like the one reported by Swinyard and Struman usually require you to hire market researchers specializing in such analyses. Even then, the likelihood of identifying segments that are useful for developing a targeting and positioning strategy is low. I explain why when I get to the section on the limitations of the STP strategy. 
Once your market segments have been identified, you will need to decide which ones to target and which ones to disregard. Different marketers offer slightly different advice about the criteria you should use in making this decision, but most would agree that attractive targets are those segments that (1) have strong sales and growth potential, (2) are relatively inexpensive to reach with marketing efforts, (3) are currently being served by few or weak competitors, and (4) have needs and desires that your company's resources are well suited to satisfy. ${ }^{12}$

Let's say that you wanted to open a restaurant in the market studied by Swinyard and Struman. If you were entering that market, you would probably find the greatest success targeting the Family Diners segment (Segment 1), because it spends the second most on dining out, has the most restaurant loyalists (which would reduce marketing costs), and has the fewest and weakest competitors. ${ }^{13}$ Having said that, I need to state the obvious here, which is that it may make the most sense to choose a concept that fits your own personality and allows you to relate to the people whom you are serving. So your own characteristics and capabilities play a crucial role in selecting target segments. A young, flamboyant, and gay restaurateur, for example, might find more success targeting the Romantics segment (Segment 2), who are less inhibited and more entertainment oriented than the other segments. Similarly, a classically trained chef with years of experience in fine dining might find the most success (not to mention personal happiness) targeting the discriminating Entertainers segment (Segment 3), despite the intense competition for that segment.

As a final consideration about the segments themselves, it's unlikely that any particular segment will be superior to others on all the criteria in question. That is, selecting segments involves a mixed picture, and there is no common metric that would permit you to make comparisons across criteria. This makes the selection of target segments an art as much as a science. You should, however, consider both the size and importance of differences between segments on each criterion when making overall evaluations of segment attractiveness.

\section{The Limits of Strategic STP Marketing}

The reason that I went into such detail about how to ferret out desirable market segments is that they must be discovered, and cannot be created. This fact is sometimes obscured by a tendency to segment markets by product subcategories (such as all-suite or extended-stay hotels) rather than by consumer characteristics. ${ }^{14}$ You can always create a new hotel subcategory, but to be successful it must satisfy the unmet needs and desires of some existing segment of consumers. The classic example is Marriott's recognition of a set of business travelers who needed a service and amenities package that 
differed from that of its existing hotels - an insight that resulted in the Courtyard concept (discussed in greater detail in the context of brand management in Chapter 24). Thus, STP marketing is helpful only if new differences between homogeneous groups of consumers actually exist, if those differences determine the consumers' choices, and if those segments are large or rich enough to justify targeting.

Useful segments should be easy to find in undeveloped markets, as occurred when Kemmons Wilson devised Holiday Inn. At that time, hotel consumers were segmented generally on the basis of desired price point, into economy, standard, and luxury. Over the years, competitors emerged to contest for each segment, and with the product tiers strategy pioneered by Quality International, the industry further subdivided the market and targeted ever narrower segments. Competition is now tight in those narrower segments, too, including such niches as extended-stay and suite hotels. At some point, all the useful segments in a market will have been identified and any further segmentation will produce segments that are insufficiently differentiated in terms of drivers of demand or too small to profitably target. ${ }^{15}$ Perhaps this has occurred in the hotel and restaurant industry, but then again, perhaps you can identify a segment that is not being served sufficiently. New brands are continually making their debut.

However, some provocative data suggest to me that most markets can be segmented only broadly. Further, it appears that those segments have already been identified in the markets of the developed world, and that attempts to further subdivide those markets are unlikely to prove useful.

Here's the study that leads me to this conclusion. Using consumer panel data on over 40 different product categories and hundreds of consumer characteristics, Rachel Kennedy and Andrew Ehrenberg compared the demographic, media usage, and psychographic characteristics of individual brand users with those characteristics of the users of all brands in that product category. ${ }^{16}$ Specifically, they recorded the percentage of each brand's purchases attributable to customers with distinct characteristics and also the percentage across brands of product category purchases attributable to customers with those characteristics. Then they calculated the differences between these brand and category percentages and averaged the resulting absolute deviations across brands, without regard to whether the deviations were positive or negative. Thus, they calculated mean absolute deviation (MAD) scores for each characteristic (see Table 23.2 for examples from the economy hotel market). ${ }^{17}$ What they found was that the typical MAD score was quite small-only 2 to 3 percentage points. Only around 8 percent of the MAD scores were more than 5 percentage points, and only 2 percent of the MAD scores were 10 percentage points or more. Moreover, the rare large MAD scores tended to reflect differences between broad subtypes within a product category (e.g., cereals aimed at kids versus those meant for 
adults) rather than brand differences within subtypes. I recently replicated these findings in the cruise and hotel industries. ${ }^{18}$ Not only that, but other studies have found that demographic and psychographic variables are poor predictors of brand choice-even though many marketers want to rely on those factors. ${ }^{19}$ Together, these empirical findings suggest that your customers are pretty much the same as those of your direct competition.

The conclusion that I reach here is that most markets are segmented enough to support broad product subtypes (say, economy hotels versus midscale with food and beverages), but not segmented enough to support more narrow differences between brands within those broad product subtypes (say, any of several economy hotel brands). After decades of competition, most if not all of the viable segments have been identified with numerous competitors vying for each. Those competitors within a product subtype end up competing for the same customers because more refined segments either do not exist or are not profitable. This explanation suggests that efforts to segment most highly competitive, well-developed, and stable markets are unlikely to identify useful new segments or targeting opportunities. The time for new segmentation efforts is when markets are new or have experienced some recent and fundamental change. For example, if social or technological changes in the market provide reason to believe that the underlying drivers of consumer choice have recently changed, then segmentation studies may identify useful new segments and targeting opportunities.

So that is the key limitation of segmentation. It may not prove strategically useful depending on what type of market you are operating in. If you are in a hotly contested and new or fundamentally changed market, then efforts to segment that market and identify a small number of segments to target may prove useful and should be attempted. However, if you are in a fairly stable, mature, competitive market (which describes most markets in the developed world), then refined segmentation and targeting are unlikely to provide the keys to competitive success. In a relatively stable and mature market, success comes not from appealing to a different set of consumers than your competition, but in finding ways to appeal to the same consumers more effectively than your competition does. ${ }^{20}$

\section{Targeting Frequent Buyers}

The tight competition in the hospitality industry has caused many brands to focus on promoting sales from frequent guests. This strategy has become so common in the hospitality industry that it deserves special mention - especially because I believe that it does not necessarily accomplish its intended goal. American Airlines led the industry's use of this strategy in the 1980s when its executives came to believe that they could increase their share of the lucrative but fickle heavy flyer segment by 
offering rewards tied to repeat patronage. Since then, the world's airlines have created over 70 frequent flyer programs that collectively have over 100 million members and give away 10 million rewards a year. Other travel-related companies were quick to copy this idea, so that frequency or loyalty programs have become commonplace in hotels, car rental firms, and even restaurants. ${ }^{21}$

This strategy seems sound because a small number of heavy users account for a large share of most product category sales and these heavy users tend to switch between several different brands within the product category. ${ }^{22}$ The frequent-guest program is designed to give heavy users a reason to be more brand loyal. The concept of setting up cumulative rewards for purchase frequency should provoke a favorable response from heavy users, as compared to light users because earning those rewards requires less change in the behavior of heavy users. Thus, loyalty programs do differentiate between two distinct customer groups. Beyond that, however, reward-based frequency or loyalty programs probably do little to increase repeat patronage because they are easy to copy and heavy users' lack of brand loyalty means that they often join multiple programs and collect rewards as a byproduct of purchases made for other reasons. ${ }^{23}$ Indeed, several studies have found that reward-based programs increase average purchase frequency only slightly if at all in the long run. ${ }^{24}$

The reward programs do help to identify your heavy users. This is theoretically useful because heavy users are easy to reach and are presumably open to marketing messages because they are already your customers. Thus, the costs of marketing to this segment (outside of the reward program) should be relatively low. The problem is that heavy users are targeted by almost everyone, so competition for their patronage is intense. Furthermore, heavy users are generally more price sensitive and deal prone than are light users, and heavy users are more likely to try new brands and switch brands. ${ }^{25}$ As most hospitality marketers have learned, this is a difficult segment in which to induce loyalty and, unless you want to permanently discount your brand, is not an attractive target.

Curious about the possible effects of loyalty programs, I conducted a study in 2008 using consumer panel data on domestic U.S. airline flights. The study was issued by Cornell's Center for Hospitality Research, ${ }^{26}$ and the data are presented in Table 23.3. I identify airlines only by a letter because disguising the airline names was a condition for obtaining the data from D. K. Shifflet. There are two things worth noting about these data. First, airlines differ substantially in penetration (the percentage of air travelers patronizing the airline at least once), but only modestly in average purchase frequency of their customers. Penetration varies from 0.3 to 17.2 percent, for an increase from smallest to largest of 5,633 percent, while average purchase frequency varies from 1.1 to 1.5 , for an increase of only 36 percent. Sales and market share are a function of the number of customers and how much they 
buy, so the wide variation in penetration and narrow variation in purchase frequency means that share of category sales is much more dependent on penetration than on purchase frequency. This relationship is shown in Figure 23.1, which depicts an almost perfect correlation between a brand's share of flights and its penetration. The differences in purchase frequency between brands do not add much at all to our understanding of the variation in brands' share of flights. Despite well-established and popular frequency programs in the airlines, differences in airline sales or share of flights are almost exclusively driven by differences in penetration-not purchase frequency.

Even if we thought purchase frequency had an effect, note that brand penetration and buyers' average purchase frequency are positively correlated, although not perfectly so (see Table 23.3). In general, brands with a large market share enjoy not only a penetration advantage but also tend to have a greater average purchase frequency than do brands 'with small shares. Conversely, small brands suffer not only from small penetration, but also a relatively low average purchase frequency among those who do buy those brands. This pattern of covariation suggests that an airline's average purchase frequency may be dependent on its level of penetration and that substantial increases in the purchase frequency may not be possible without increasing penetration. If that is true (and it seems to be the case), then marketing efforts aimed exclusively at increasing purchase frequency among heavy users are doomed to failure.

Table 23.3

Data on 19 Domestic U.S. Airlines

\begin{tabular}{|c|c|c|c|c|c|}
\hline Airline & $\begin{array}{l}\text { Number of } \\
\text { Customers }\end{array}$ & Penetration & $\begin{array}{l}\text { Purchase } \\
\text { Frequency }\end{array}$ & $\begin{array}{l}\text { Market } \\
\text { Share }\end{array}$ & $\begin{array}{l}\text { Travel } \\
\text { Frequency }\end{array}$ \\
\hline A & $5,100.00$ & 0.172 & 1.41 & 0.156 & 1.70 \\
\hline B & $4,740.00$ & 0.160 & 1.42 & 0.147 & 1.74 \\
\hline $\mathrm{C}$ & $4,290.00$ & 0.145 & 1.34 & 0.125 & 1.62 \\
\hline $\mathrm{D}$ & $3,621.00$ & 0.122 & 1.50 & 0.119 & 1.84 \\
\hline$E$ & $3,016.00$ & 0.102 & 1.40 & 0.092 & 1.65 \\
\hline $\mathrm{F}$ & $2,785.00$ & 0.094 & 1.33 & 0.081 & 1.63 \\
\hline G & $2,165.00$ & 0.073 & 1.40 & 0.066 & 1.73 \\
\hline $\mathrm{H}$ & $1,068.00$ & 0.036 & 1.29 & 0.030 & 1.66 \\
\hline I & 862.00 & 0.029 & 1.32 & 0.025 & 1.68 \\
\hline $\mathrm{J}$ & 643.00 & 0.022 & 1.26 & 0.018 & 1.62 \\
\hline $\mathrm{K}$ & 588.00 & 0.020 & 1.22 & 0.016 & 1.52 \\
\hline $\mathrm{L}$ & 526.00 & 0.018 & 1.33 & 0.015 & 1.61 \\
\hline M & 307.00 & 0.010 & 1.18 & 0.008 & 1.59 \\
\hline $\mathrm{N}$ & 272.00 & 0.009 & 1.27 & 0.008 & 1.46 \\
\hline $\mathrm{O}$ & 227.00 & 0.008 & 1.30 & 0.006 & 1.65 \\
\hline Q & 149.00 & 0.005 & 1.15 & 0.004 & 1.48 \\
\hline S & 112.00 & 0.004 & 1.14 & 0.003 & 1.32 \\
\hline V & 79.00 & 0.003 & 1.24 & 0.002 & 1.61 \\
\hline $\mathrm{W}$ & 78.00 & 0.003 & 1.19 & 0.002 & 1.56 \\
\hline
\end{tabular}

Note: Four foreign airlines that primarily serve international travelers and enjoy competitive advantages in serving those markets that the domestic airlines do not have been omitted.

Source: Reproduced by permission from M. Lynn, "Frequency Strategies and Double Jeopardy in Marketing: The Pitfall of Relying on Loyalty Programs," Cornell Hospitality Report 8(2) (2008):10. 
By themselves, the data in Table 23.3 speak only to the airline industry. However, the two patterns displayed in those data are so common that they have been identified as the double jeopardy effect. This name comes from the tendency for small share brands to suffer in two ways-from lower penetration and lower average purchase frequency. It also refers to the wider variation in penetration than in purchase frequency as well as to the positive correlation between these measures. The double jeopardy effect has been observed in over 50 different common product categories-including breakfast cereals, gasoline, and soap-as well as in retail stores and even television programs. It has also been documented in many markets around the world, including Australia, continental Europe, Japan, the United Kingdom, and the United States. This effect seems to be a universal characteristic of mature, stable markets where competing brands are largely similar and can substitute for one another. ${ }^{27}$

Since most hospitality firms operate in mature, stable markets, the double jeopardy effect suggests that marketing strategies aimed solely at increasing the repeat patronage of heavy users are unlikely to succeed for hotels, airlines, and other such companies. I'm not suggesting that you abandon your loyalty program because you probably need it as a defensive measure to prevent the loss of market share to competitors with similar programs. ${ }^{28}$ Instead, I'm suggesting that your marketing efforts should focus on increasing the popularity of your brand among all the users in your product category or subcategory-with the idea of boosting your penetration.

Figure 23.1

Relationship between Share of Flights and Penetration for 19 Domestic Airlines in the United States

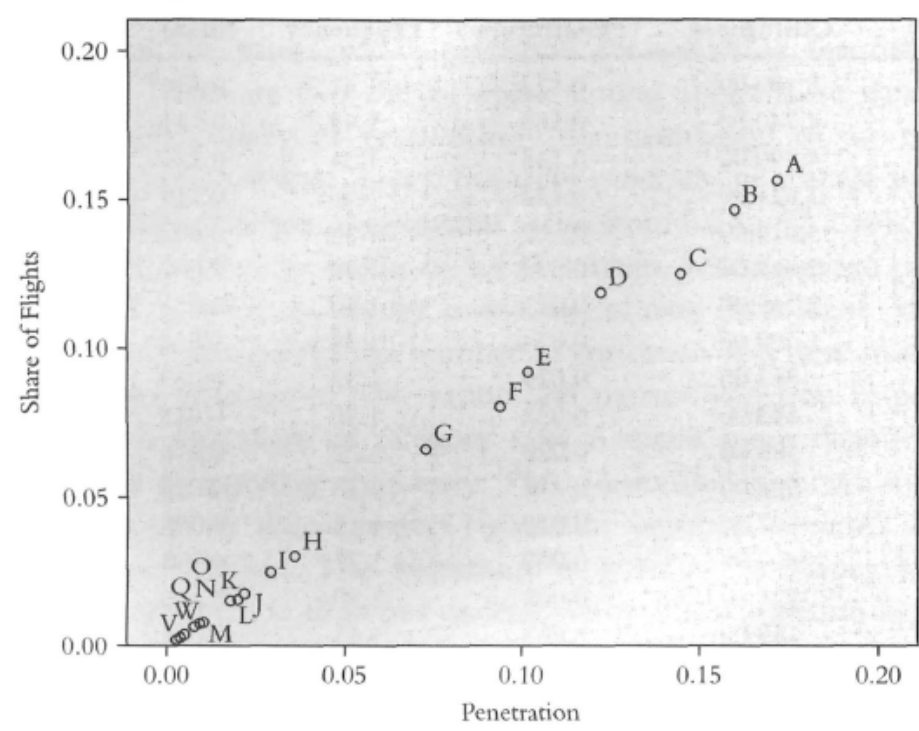




\section{Summary}

If by chance you are entering a new or underdeveloped market, the STP strategy will offer you a strategic advantage over competitors. You can divide the market into homogeneous groups, identify those groups that your firm is best suited to satisfy, and target those selected groups. This focus will allow you to better and more cost effectively meet the needs of the target segments than can competitors who are going after everyone (or no one in particular). Needless to say, competitive forces mean that any successful strategy will eventually be copied, along with efforts you might make to identify and target even narrower segments. So it is in most geographic markets of the hospitality industry: Mature, stable markets have typically been segmented as much as is practical with several competitors vying for each profitable segment. Despite excellent product development efforts over the years, further segmentation and targeting are rarely helpful in such markets. Even the intuitively appealing division of the market into light and heavy users and the strategy of targeting the heavy-user segment is unlikely to succeed in crowded, mature markets. Instead, you are best advised to target all the users of your product category or subcategory in such markets, with a goal of increasing your penetration. Sales increases will be obtained, if at all, from increasing your brand's relative popularity among all users of the product class.

As a concluding point, given the different strategies best pursued in these two different markets - new or underdeveloped and mature or stable markets - it is important to know which you operate in. Although I believe that the data indicate that most markets are mature and stable, don't assume that you are operating in such a market. Instead, as I suggested previously, you should hire marketing researchers who will collect data on hundreds of variables and use sophisticated statistical procedures to try to segment your market, with a goal of identifying profitable new segments to target. If a plausible argument can be made that such profitable new target segments have been found, then pursue them. If not, you probably are operating in a stable market that has already been segmented as much as it can bear. Certainly, repeated failures by different market research firms to identify profitable new segments to target would be evidence that you are operating in such a market. In that case, try to get to know the users of your product category or subcategory so that you can satisfy their needs better than do your competitors. I believe that adhering to this contingent strategic focus is the path to greater profits in the hospitality industry.

\footnotetext{
${ }^{1}$ For example, see P. Kotler, Marketing Management, 9th ed. (Upper Saddle River, NJ: Prentice Hall, 1997).

${ }^{2}$ D. Aaker, Managing Brand Equity (New York: Free Press, 1991), 164.
} 
${ }^{3}$ P. Kotler, J. T. Bowen, and J. C. Makens, Marketing for Hospitality and Tourism, 4th ed. (Upper Saddle River, NJ: Prentice Hall, 2006), 278-279.

${ }^{4}$ http://en-us.nielsen.com/tab/product_families/nielsen_claritas/prizm, March 18,2010.

${ }^{5}$ http://en.wikipedia.org/wiki/Claritas_Prizm, May 10, 2010.

${ }^{6}$ Ibid.

${ }^{7}$ See K. Clancy and P. Krieg, Your Gut Is Still Not Smarter than Your Head (Hoboken, NJ: Wiley, 2007), 59-80.

${ }^{8}$ P. R. Dickson and J. L. Ginter, "Market Segmentation, Product Differentiation, and Marketing Strategy," Journal of Marketing (April 1987): 1-10.

${ }^{9}$ S. Dibb, "Criteria Guiding Segmentation Implementation: Reviewing the Evidence,"' Journal of Strategic Marketing! (1999): 107-129

${ }^{10}$ W. R. Swinyard and K. D. Struman, "Market Segmentation: Finding the Heart of Your Restaurant's Market," Cornell Hotel and Restaurant Administration Quarterly 37 (1) (May 1986): 88-96.

${ }^{11}$ Ibid.

${ }^{12}$ Dibb, 1999.

${ }^{13}$ Swinyard and Struman, 1986.

${ }^{14}$ Dickson and Ginter, 1987.

${ }^{15}$ R. Kennedy, and A. Ehrenberg, "There Is No Brand Segmentation," Marketing Research (Spring 2001): 4 - 7. 16 Ibid.

${ }^{17}$ Modified from M. Lynn, "Brand Segmentation in the Hotel and Cruise Industries: Fact or Fiction?" Cornell Hospitality Report 7(4) (2007): 12.

${ }^{18}$ K. Hammond, A. S. C. Ehrenberg, and G.J. Goodhardt, "Market Segmentation for Competitive Brands," European Journal of Marketing 30(12) (1996): 39-49; Ibid.

19 Ibid.; J. Dawes, "Interpretation of Brand Penetration Figures that Are Reported by Sub-groups," Journal of Targeting, Measurement and Analysis for Marketing 14(2) (2006): 173-183.; and G. Fennel, G. M. Allenby, S. Yang, and Y. Edwards, "The Effectiveness of Demographic and Psychographic Variables for Explaining Brand and Product Category Use," Quantitative Marketing and Economics 1 (2003): 223-244.

${ }^{20}$ Hammond, Ehrenberg, and Goodhardt, 1996.

21 "History of Loyalty Programs," www.frequentflier.com/ffp-005.htm, February 3, 2008.

${ }^{22}$ G. Hallberg, All Consumers Are Not Created Equal (New York: Wiley, 1995).

${ }^{23}$ B. Berman, "Developing an Effective Customer Loyalty Program," California Management Review 49(1) (2006): 123-148.

${ }^{24}$ J. Leenheer, H. J. vanHeerde, T. H. A. Bijmolt, and A. Smidts, "Do Loyalty Programs Enhance Behavioral Loyalty? An Empirical Analysis Accounting for Self-Selecting Members," International Journal of Research in Marketing 24 (2007): 31 - 47; L. Meyer-Waarden and C. Benavent, "The Impact of Loyalty Programs on Repeat Purchase Behavior," Journal of Marketing Management 22 (2006): 61-88.; and B. Sharp and A. Sharp, "Loyalty Programs and Their Impact on Repeat-Purchase Loyalty Patterns," International Journal of Research in Marketing 14 (1997): 473486.

${ }^{25}$ E. C. Hackelman and J. M. Duker, "Deal Proneness and Heavy Usage: Merging Two Market Segmentation Criteria," Journal of the Academy of Marketing Science 8(4) (1980): 332-344; Hallberg, 1995; and B. D. Kim and P. E. Rossi, "Purchase Frequency, Sample Selection, and Price Sensitivity: The Heavy User Bias," Marketing Letters 5(1) (1994): 57-67; and J. W. Taylor, "A Striking Characteristic of Innovators," Journal of Marketing Research 14 (February 1977): 104-107.

${ }^{26}$ M. Lynn, "Frequency Strategies and Double Jeopardy in Marketing: The Pitfall of Relying on Loyalty Programs," Cornell Hospitality Report 8(2) (2008).

${ }^{27}$ A. A. C. Ehrenberg, G. J. Goodhardt, and T. P. Barwise, "Double Jeopardy Revisited, Journal of Marketing 54 (July 1990): 82-91.

${ }^{28}$ M. D. Uncles, G. R. Dowling, and K. Hammond, "Customer Loyalty and Customer Loyalty Programs, Journal of Consumer Marketing 20(4) (2003): 294-316. 